\title{
Commentary: Is seeing believing?
}

\author{
Aaron Bettenhausen, MD, and Dawn S. Hui, MD
}

\footnotetext{
From the Department of Cardiothoracic Surgery, Long School of Medicine, University of Texas Health Science Center at San Antonio, San Antonio, Tex.

Disclosures: Authors have nothing to disclose with regard to commercial support.

Received for publication April 7, 2019; accepted for publication April 8, 2019; available ahead of print May 23, 2019.

Address for reprints: Dawn S. Hui, MD, 7703 Floyd Curl Dr, Suite 211L, San Antonio, TX 78229 (E-mail: dawn. hui@gmail.com)

J Thorac Cardiovasc Surg 2019;158:e85-6

0022-5223/ $\$ 36.00$

Copyright (C) 2019 by The American Association for Thoracic Surgery

https://doi.org/10.1016/j.jtcvs.2019.04.024
}

In this edition of the Journal, Kondo and colleagues ${ }^{1}$ report their single experience with using central retinal artery (CRA) Doppler flow ultrasonography as a means of monitoring cerebral perfusion during a debranching thoracic endovascular aortic repair. Their patient presented with a saccular aortic arch aneurysm, which was complicated by severe cerebrovascular disease and an incomplete circle of Willis. On clamping of the left carotid artery, CRA flow diminished quickly, whereas cerebral regional oxygen saturation $\left(\mathrm{rSO}_{2}\right)$ dropped in the course of minutes. The patient's blood pressure was pharmacologically increased to optimize cerebral perfusion, and CRA flow subsequently improved.

CRA Doppler flow ultrasonography is an intriguing new adjunct for neurovascular monitoring during complex aortic surgery. Although $\mathrm{rSO}_{2}$ has been the traditional mode of cerebral perfusion monitoring particularly, in complex aortic cases, there are limitations. These include variations in sensitivity across devices and the inability to monitor the entire cerebrum. Interpretation of values and trends is challenging due to wide variations in baseline values. ${ }^{2,3}$ These limitations may explain the findings of a systematic review by Zheng and colleagues," in which they state that "data are insufficient to conclude that interventions to improve $\mathrm{rScO}_{2}$ desaturation prevent stroke or POCD [postoperative cognitive dysfunction]." Adjuncts to help interpret $\mathrm{rSo}_{2}$ include transcranial Doppler flow ultrasonography, bispectral index monitoring, and electroencephalographic monitoring. Regardless, monitoring $\mathrm{rSO}_{2}$ still has clinical merit, because clinical judgment can help abrogate the potential pitfalls of this technology.

CRA Doppler flow ultrasonography, as presented in this case, potentially allows a more direct assessment cerebral perfusion. Kondo and colleagues case report ${ }^{1}$ narrates a seemly simple cause and effect; however, there are more variables to consider when interrupting the data provided by this technology. The lack of posterior cerebral monitoring may cloud the clinical picture for patients with a known intact circle of Willis. Would diminished

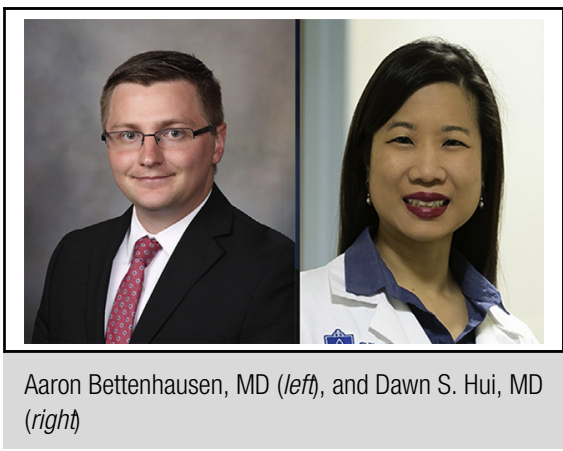

Central Message

Central retinal artery Doppler flow imaging is an intriguing adjunct for neurovascular monitoring. It may be of utility, given the limited evidence basis for standard cerebral monitoring techniques.

See Article page e81.

CRA flow be a warning sign of ongoing cerebral ischemia? Should the team be reassured by the stable $\mathrm{rSo}_{2}$, or should they take action? Obviously, a single experience cannot shed light on the multitude of scenarios that could exist with this new technology. With that in mind, it has been suggested in a small patient series that sustained hypoperfusion detected by CRA flow ultrasonography is associated with neurologic complications. ${ }^{5}$

Stroke remains one of the most devastating complications during cardiac surgery, and those undergoing complex aortic surgery present a particular challenge. Although $\mathrm{rSO}_{2}$ monitoring continues to be one of the more conventional modalities, CRA Doppler flow ultrasonography represents another possible adjunct in monitoring cerebral perfusion during aortic surgery. For now, its clinical relevance is limited by its lack of objective efficacy. Both modalities would benefit from further study.

\section{References}

1. Kondo N, Hirose N, Kihara K, Orihashi K. Cerebral perfusion in debranching thoracic endovascular aortic repair monitored by orbital ultrasonography. J Thorac Cardiovasc Surg. 2019;158:e81-3.

2. Chan MJ, Chung T, Glassford NJ, Bellomo R. Near-infrared spectroscopy in adult cardiac surgery patients: a systematic review and meta-analysis. J Cardiothorac Vasc Anesth. 2017;31:1155-65

3. Holmgaard F, Vedel AG, Langkilde A, Lange T, Nilsson JC, Ravn HB. Differences in regional cerebral oximetry during cardiac surgery for patients with or without postoperative cerebral ischaemic lesions evaluated by magnetic resonance imaging. Br J Anaesth. 2018;121:1203-11. 
4. Zheng F, Sheinberg R, Yee MS, Ono M, Zheng Y, Hogue CW. Cerebral near-infrared spectroscopy monitoring and neurologic outcomes in adult cardiac surgery patients: a systematic review. Anesth Analg. 2013;116:663-76.
5. Orihashi K, Matsurro Y, Sueda T, Shikata H, Watari M, Okada K. Clinical implication of orbital ultrasound monitoring during selective cerebral perfusion. Ann Thorac Surg. 2001;71:673-7. 